\title{
Multiple Sclerosis Presenting as Isolated Oculomotor Nerve Palsy
}

\author{
Ryan J. Uitti and A.H. Rajput
}

\begin{abstract}
A 23-year old woman came to the emergency room with an isolated oculomotor nerve palsy (including pupillary dilatation) of rapid onset. Investigations and history revealed no cause. The subsequent course of events indicated a diagnosis of multiple sclerosis. While the third nerve has been shown to be involved during the course of multiple sclerosis, this is the first report of a case presenting as an isolated oculomotor nerve paralysis.
\end{abstract}

RÉSUMÉ: La paralysie isolée du nerf moteur oculaire commun comme manifestation initiale de la sclérose en plaques. Une femme âgée de 23 ans se présente à la salle d'urgence avec une paralysie isolée du nerf moteur oculaire commun (incluant une dilatation pupillaire) à début brusque. L'investigation et l'histoire sont non contributives. L'évolution subséquente de la maladie révèle un diagnostic de sclérose en plaques. Même s'il a été démontré que le troisième nerf crânien peut être atteint à un moment ou l'autre de l'évolution de la sclérose en plaques, nous rapportons pour la première fois un cas dont la manifestation initiale de la maladie est une paralysie isolée du nerf moteur oculaire commun.

Can. J. Neurol. Sci. 1986; 13:270-272

The onset of multiple sclerosis (MS) is monosymptomatic in approximately $45 \%$ of cases. ' When the disease presents as an isolated cranial nerve deficit the most common site of lesion is the optic nerve. ${ }^{2}$ Although the oculomotor nerve may be involved in as many as $12 \%$ of cases sometime during the course of the illness, ${ }^{3}$ oculomotor nerve paralysis as the initial presentation of MS has never been reported. We report a case of MS that presented as an isolated third nerve palsy with pupillary involvement.

\section{CASe Report}

A 23-year-old woman was seen in the emergency room at University Hospital, Saskatoon, March 1, 1983, for double vision and a droopy right upper eyelid. One month earlier she had experienced a flu-like illness from which she recovered completely. On February 25th, 1983 she felt that her right eye was becoming puffy. Over the subsequent two days her right upper lid closed completely, the right eye became painful and she developed horizontal diplopia and blurred vision.

There was no previous history of visual problems and until this episode she was not subject to headaches. She had been taking birth control pills for the past 2-3 years and 2 years before she had been hospitalized for anxiety and depression. She also had a history of "recurrent bladder infections" and claimed that her right hand suffered "cramps" with changes in weather.

On March 1 , in the emergency room neurological abnormalities were restricted to the patient's right eye. There was complete ptosis, mydriasis, and total impairment of upward and medial eye movements; downward gaze was possible. The right pupil was dilated and nonreactive to light and accomodation. Optic fundi were normal. A provisional diagnosis of posterior communicating aneurysm was made. The patient did not cooperate for a satisfactory CT study to be performed. A right carotid angiogram was performed on March 4th and showed no abnormalities. A lumbar puncture carried out on March 7th revealed normal pressure and the fluid was clear. The WBC count, protein, glucose, and protein electrophoresis were normal. A CT contrast enhanced scan on March 7th showed normal orbits, midbrain, and brain (Figure 1). Since her hospitalization she complained of a right frontal/temporal dull headache, but there was progressive improvement in her ophthalmoplegia. Examination on March 7th revealed that the right upper eyelid could now be elevated to show the lower half of the cornea, the right pupil size was closer to normal, and some constriction to light was evident.

On March 8th the patient felt nauseated and vomited once. Two days later she experienced unsteadiness of gait and was noted to have generalized hyperreflexia and bilateral extensor plantar responses. She had gait and appendicular ataxia and decomposition of rapid alternating movements; however, power and sensation remained normal. There was also a change in her affect; she was inappropriately euphoric. An EEG on March 10th showed recurrent delta wave discharges in the right temporal region. The following day she developed numbness of the right arm and leg, and slight weakness of the right leg was observed.

By March 14th the third nerve palsy had regressed completely. However, by then, she had demonstrable weakness and ataxia of the right lower limb, bilateral extensor plantar responses and her speech was dysprosodic. Visual evoked potentials were at the upper limits of normal in both eyes. On March 14th another non-enhanced CT scan was normal but the patient refused a contrast study. Four days later, a CT scan using double dose contrast and delayed technique revealed multiple small enhancing lesions, the largest one measuring just over

From the Department of Clinical Neurological Sciences, University of Saskatchewan, Saskatoon, Saskatchewan.

Received December 5, 1985. Accepted March 4, 1986.

Reprint requests to: Dr. A.H. Rajput, Professor of Neurology, University Hospital, Saskatoon, Saskatchewan, Canada S7N 0X0 


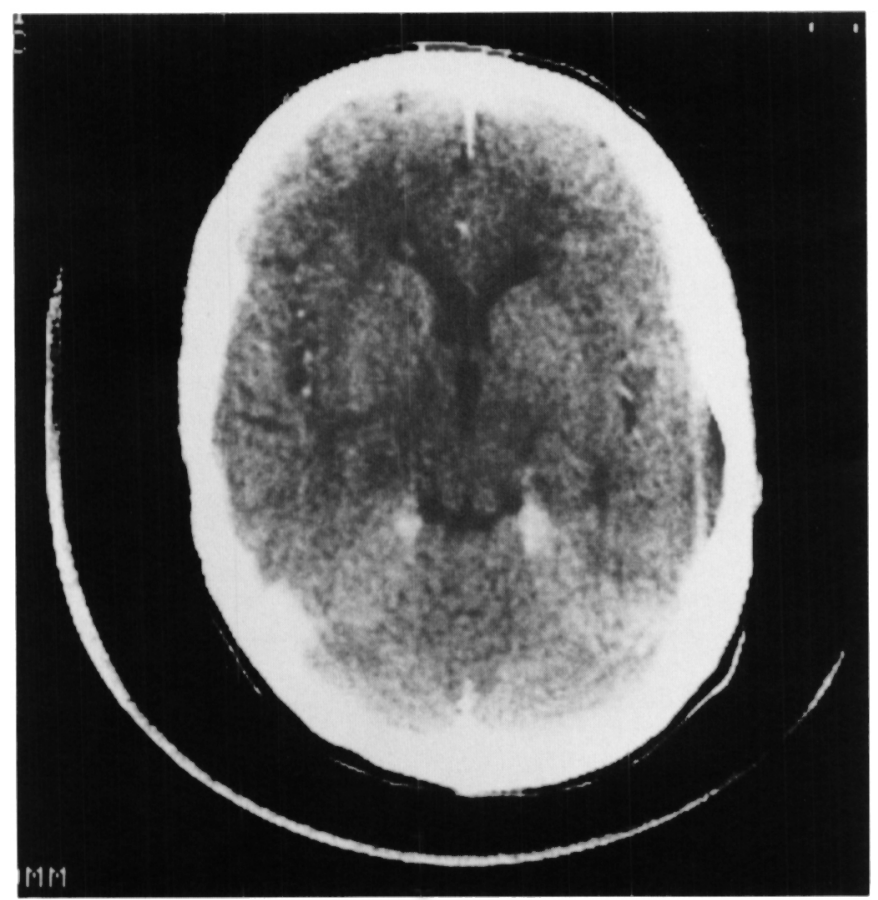

Figure I-Contrast enhanced CT scan of March 7th showing no obvious abnormalities.

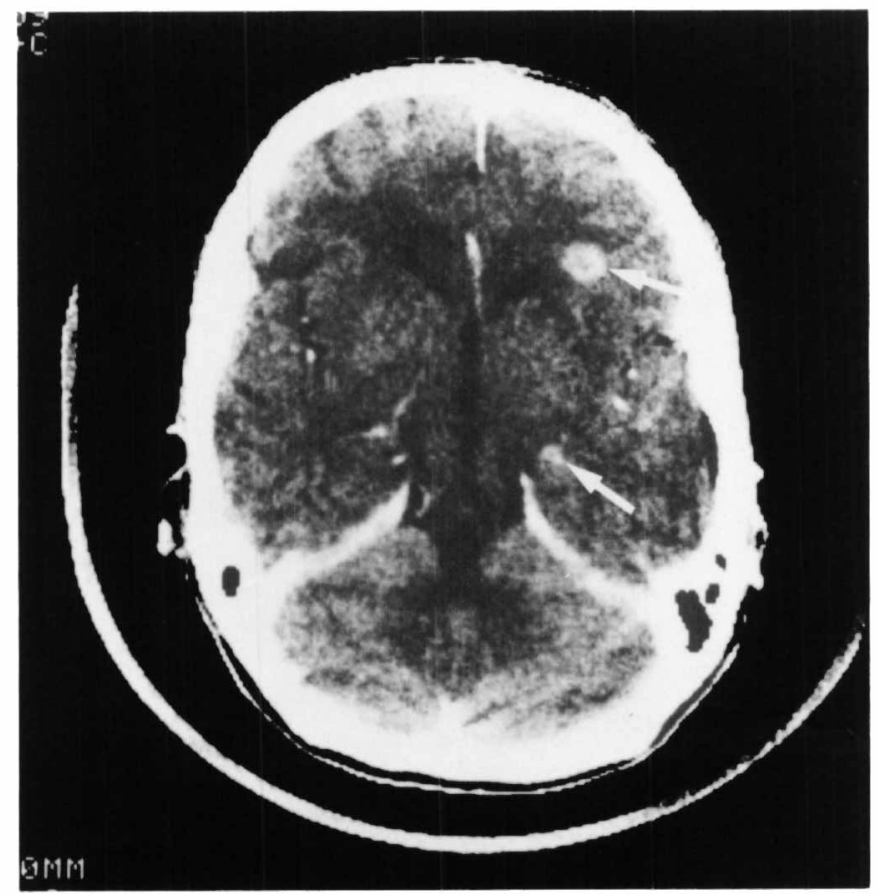

Figure 2-Double dose contrast and delayed technique CT scan of March 18th showing two enhancing lesions (arrows).

$1 \mathrm{~cm}$ lateral and inferior to the tip of the left frontal horn (Figure 2). These lesions were consistent with MS plaques. The patient continued to have relapsing and incompletely remitting neurologic deficits. The subsequent course included asymmetric weakness in all extremities and incontinence. By May 28, 1985 she had become wheelchair bound and required continual nursing care. A double dose contrast CT scan performed on July 19, 1985 revealed no abnormalities. She has been hospitalized for the past nine months at the time of this writing.

\section{Discussion}

In S. Poser's extensive analysis of $812 \mathrm{MS}$ cases third nerve involvement was noted sometime during the course of illness in $12 \%$ of cases (diplopia in $9 \%$ and pupillary abnormalities in $3 \%),{ }^{3}$ although it was less common in Savitsky and Rangell's series and review. ${ }^{4}$ Ptosis, as a manifestation of MS, is rare. ${ }^{1.5}$ In one large autopsy proven series ptosis was reported in only $2 \%$ of cases. ${ }^{5}$ Complete ptosis, as seen in our patient, is believed to be extremely uncommon. 'In general, an isolated third nerve palsy is a rare occurrence in MS and E.B. Matthews in his review (1985) contends that "an isolated third nerve palsy should not suggest a diagnosis of MS." 'We were unable to find a single documented case of MS presenting as an isolated third nerve palsy with pupillary dilatation.

Our patient presented with rapidly progressive oculomotor paralysis. At the time of admission she had third nerve paralysis and was thought to have an aneurysm. An angiogram was performed to rule out that possibility. Neither the angiogram nor the initial CT scan nor any other laboratory test made us suspect the correct diagnosis early on. Because the onset of MS as third nerve paralysis (with pupillary involvement) had never been documented before, that possibility was not entertained until further evolution of the illness. Ten days after admission, while the patient was recovering from ophthalmoplegia, she developed signs indicative of widespread brainstem dysfunction.

Third nerve paralysis of rapid onset, associated with pupillary dilatation, has been regarded as indicative of a surgical lesion, ${ }^{6}$ the most common surgical lesion being an aneurysm in the internal carotid-posterior communicating artery region. ${ }^{6}$ Although the medical versus surgical third nerve palsy distinction is useful in clinical practice, the early absence of pupillary dilatation is not always a reliable index. One recent report indicated that approximately $15 \%$ of aneurysm-induced third nerve palsy cases had normal pupils at the time of initial presentation, and that pupillary dilatation ensued within one week. 7

On the other hand, $34 \%$ of third nerve palsies with pupil dilatation represent non-surgical and relatively benign lesions. ${ }^{6}$ The common causative diseases in this category are diabetes mellitus and vascular disease (hypertension or arteriosclerosis), with ophthalmoplegic migraine, sinus (maxillary, ethmoidal, or frontal) inflammation, and syphilis also being reported. ${ }^{6,8,9}$ Head injury without fracture or other surgical lesions may also present as a third nerve palsy. ${ }^{10}$

Our patient suffered from none of the above diseases, had no surgical lesions, or history of head injury. The subsequent course of her illness leaves no doubt that she suffers from MS. Oculomotor nerve palsy may rarely occur in MS during the course of illness. ${ }^{2}$ The evolution of ophthalmoplegia in this case indicates that it was caused by a MS lesion.

We believe that the third nerve lesion was extranuclear in this patient. A nuclear lesion would produce contralateral paralysis of the superior rectus or bilateral ptosis, and a fascicular lesion may be a part of Claude syndrome, Weber syndrome, Benedict syndrome, or Nothnagel syndrome. " The MS plaque, we believe, was located in the third nerve fascicle immediately proximal to its exit from the brainstem, prior to passage through the cavernous sinus. The demyelination in this region was not complete as downward movement of the right eye was spared.

CT scanning is helpful in the diagnosis of MS. Low density, enhancing lesions are recognized in $21-35 \%$ of cases with a 
tentative or certain diagnosis of MS using double dose contrast CT scans. ${ }^{12,13}$ Other nonspecific CT abnormalities - e.g. cortical atrophy and enlarged ventricles are also seen. In $80 \%$ of longstanding, clinically definite MS cases some CT abnormality is found. ${ }^{12}$ Because CT scanning carries lower risk than angiography, in those cases where third nerve palsy with pupillary dilatation occurs without dramatic headache and/or evidence of meningeal irritation, a double dose contrast enhanced $\mathrm{CT}$ scan would be a reasonable investigation in conjunction with angiography.

The course of MS has been rapidly disabling in our patient. Whether onset of MS as an oculomotor nerve palsy indicates a poor prognosis cannot be ascertained from the literature.

Our case demonstrates the potential diagnostic complexity of an isolated third nerve palsy.

\section{REFERENCES}

1. Matthews WB. Symptoms and signs. In: McAlpine's Multiple Sclerosis, Matthews WB, ed. Edinburgh: Churchill Livingstone, 1985: 97, 130.

2. Wikstrom J, Poser S, Ritter G. Optic neuritis as an initial symptom in multiple sclerosis. Acta Neurol Scandinav 1980; 61: 178-185.
3. Poser S. Multiple Sclerosis. Berlin: Springer-Verlag, 1978: 34

4. Savitsky N, Rangell L. The ocular findings in multiple sclerosis. Assoc Res Nerv Ment Dis 1950; 28: 403-413.

5. Poser CM, Presthus J, Horsdal O. Clinical characteristics of autopsyproved multiple sclerosis. A study of British, Norwegian, and American cases. Neurology 1966; 16: 791-798.

6. Green WR, Hackett ER, Schlezinger NS. Neuro-ophthalmologic evaluation of oculomotor nerve paralysis. Arch Ophth 1964; 72 : 154-167.

7. Kissel JT, Burde RM, Klingele TG, Zeiger HE. Pupil-sparing oculomotor palsies with internal carotid-posterior communicating artery aneurysms. Ann Neurol 1983; 13: 149-154.

8. Friedman AP, Harter DH, Merritt HH. Ophthalmoplegic migraine. Arch of Neurol 1962; 7: 320-327.

9. Rush JA, Younge BR. Paralysis of cranial nerves III, IV, and VI. Cause and prognosis in 1,000 cases. Arch Ophthalmol 1981; 99 : 76-79.

10. Memon MY, Paine KWE. Direct injury of the oculomotor nerve in craniocerebral trauma. J Neurosurg 1971; 35: 461-464.

11. Leigh RJ, Zee DS. The Neurology of Eye Movements. Philadelphia: F.A. Davis Company, 1983: 172.

12. Gyldensted C. Computer tomography of the cerebrum in multiple sclerosis. Neuroradiology 1976; 12: 33-42.

13. Heshy LA, Gado MH, Trotter JL. Computerized tomography in the diagnostic evaluation of multiple sclerosis. Ann Neurol 1979; 5: 32-39. 